\title{
Telerehabilitation for patients with breast cancer through the COVID-19 pandemic
}

\author{
Laura Ferreira de Rezende $^{1}$ (D) $\cdot$ Vinícius Emanoel Francisco ${ }^{1} \cdot$ Ricardo Laier Franco $^{1}$
}

Received: 21 August 2020 / Accepted: 2 September 2020 / Published online: 10 September 2020

(c) Springer Science+Business Media, LLC, part of Springer Nature 2020

\section{To the editor,}

Adapting face-to-face physical therapy rehabilitation in breast cancer care to a model of telerehabilitation has been necessary and can be an alternative for continuing physical therapy treatment $[1,2]$. The research on models of telerehabilitation for patients with breast cancer is scarce. This strategy focuses on decreasing the side effects of breast cancer surgery, which include lymphedema, limited movement in the upper limbs, fatigue, and muscle strength loss. Considering the health risk of face-to-face appointments, telerehabilitation might be adopted as first option to maintain assistance to breast cancer patients.

\section{Examination}

The physical examination has to be modified to accommodate to the virtual method. Active ranges of motion and movements of directional preference are visually assessed. Many provocative tests are performed by the patient through verbal and demonstrative guidance. The patient is educated about how to measure the girth of upper limbs obtaining its volumes with a tape measure focusing anatomical points used in the Cleveland Clinic webpage: Breast Cancer-Arm Volume Calculator [1].

\section{Lymphedema}

Patients are educated and/or supervised on manual lymphatic self-drainage, functional compressive bandaging, and therapeutic exercise. These orientations are done to promote

Laura Ferreira de Rezende rezendelaura@hotmail.com

1 PhysicalTherapy Department, Centro Universitário das Faculdades Associadas de Ensino - UNIFAE, Largo Engenheiro Paulo Almeida Sandeville, 15, São João da Boa Vista, SP, Brazil lymphatic and venous return of the upper limbs and can be daily or at least 3 times a week.

\section{Range of movement (ROM) modality}

Early intervention of shoulder joint mobilization plays an important role for preservation of shoulder kinematics and prevention of adhesions. Pendulum exercises decrease the pain through the effect of distraction and oscillation. It should be done three times a day [3]. Directed exercises of flexion, abduction, and external rotation are more efficient in the rehabilitation of ROM than the performance of free shoulder exercises and should be prescribed since first postoperative day [4]. Abduction, flexion, and functional diagonal of the shoulder-stretching maintained at least for $30 \mathrm{~s}$ are recommended (Fig. 1).

\section{Fatigue and muscle strength}

A multicomponent exercise program is considered to be the most adequate for breast cancer patient, especially aerobic and resistance training exercises (Fig. 1). It should be done 5 days a week, with adaptation in volume and intensity, at least 150 to $300 \mathrm{~min} /$ week of aerobic exercise (moderate intensity $-40-60 \%$ heart rate reserve or $65-75 \%$ of maximal heart rate) and two resistance training sessions per week [5].

\section{Examples of home exercises}

In case one does not have specific materials for training, the following options are available in any house for ROM exercises as moving up a wall with the fingers until the maximum limit of flexion and abduction, brushing the hair, or performing shoulder rolls and arm rotation, for muscle strength transporting items with light and moderate 
Fig. 1 Exercises examples that can be done throught telerehabilitation

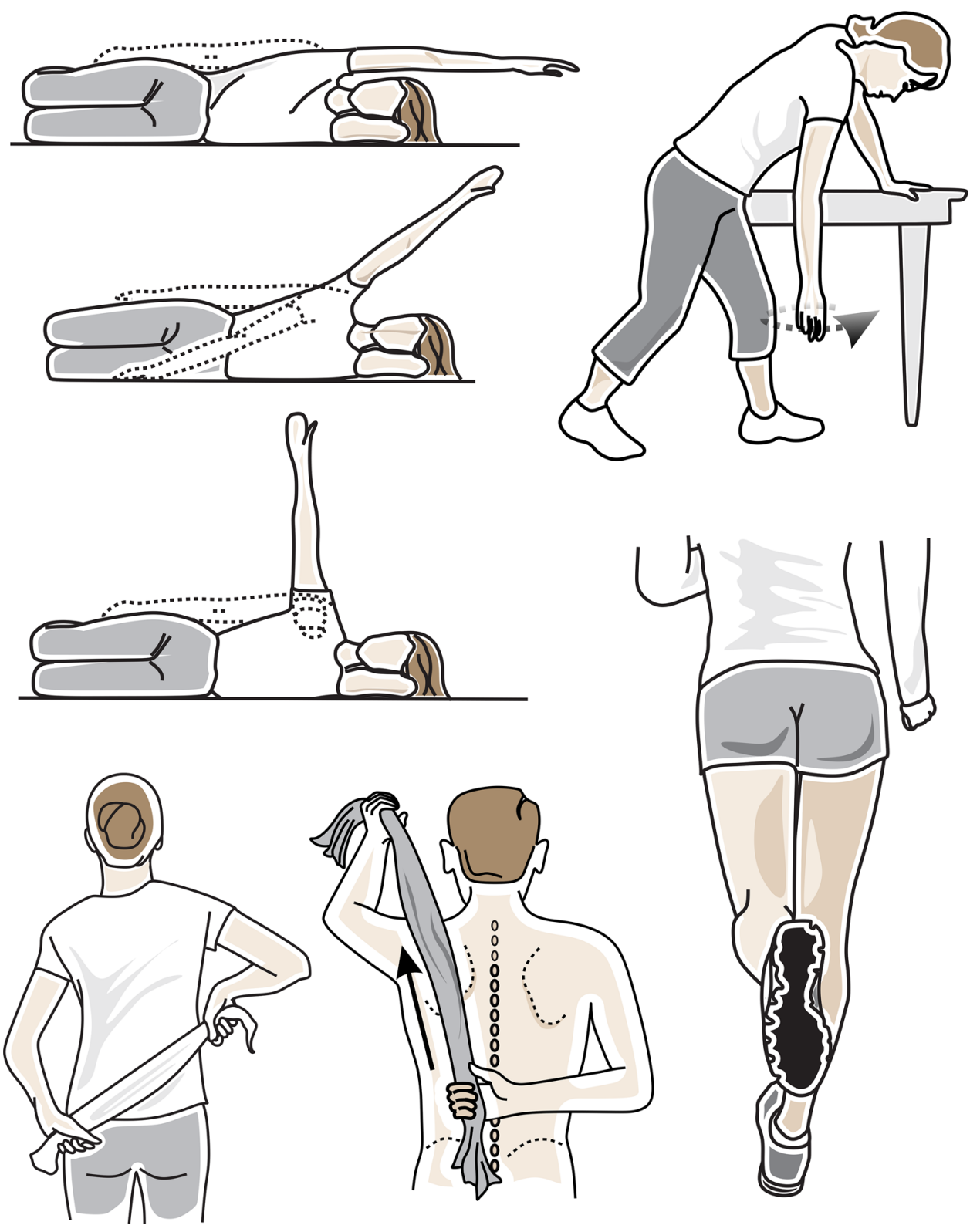

weights (vegetables, rice, water, etc.) can be done, and for aerobic exercises walking inside the house or dancing.

Funding This study was funded by Conselho Nacional de Desenvolvimento Científico e Tecnológico—428926/2016-9.

\section{Compliance with ethics standards}

Conflict of interest The authors declare that they have no conflicts of interest.

Research involving human participants and/or animals Not applicable.

Informed consent Not applicable.

\section{References}

1. Mella-Abarca W, Barraza-Sánchez V, Ramírez-Parada K (2020) Model of telerehabilitation for people with breast cancer during the COVID-19 pandemic in Chile. ecancer 14:1085

2. Green BN, Pence TV, Kwan L, Rokicki-Parashar J (2020) Rapid deployment of chiropractic telehealth at 2 worksite health centers in response to the COVID-19 pandemic: observations from the field. J Manipulative Physiol Ther S0161-4754(20):30129-30139

3. Akkaya N, Akkaya S, Gungor HR, Yaşar G, Atalay NS, Sahin F (2017) Effects of weighted and un-weighted pendulum exercises on ultrasonographic acromiohumeral distance in patients with subacromial impingement syndrome. J Back Musculoskelet Rehabil 30(2):221-228 
4. de Rezende LF, Franco RL, de Rezende MF, Beletti PO, Morais SS, Gurgel MS (2006) Two exercise schemes in postoperative breast cancer: comparison of effects on shoulder movement and lymphatic disturbance. Tumori 92(1):55-61

5. Jiménez-Pavón D, Carbonell-Baeza A, Lavie CJ (2020) Physical exercise as therapy to fight against the mental and physical consequences of COVID-19 quarantine: Special focus in older people. Prog Cardiovasc Dis 63(3):386-388
Publisher's Note Springer Nature remains neutral with regard to jurisdictional claims in published maps and institutional affiliations. 